\title{
Bitcoin Returns and the Frequency of Daily Abnormal Returns
}

\author{
Guglielmo Maria Caporale, ${ }^{*}$ Alex Plastun,${ }^{\dagger}$ Viktor Oliinyk ${ }^{\ddagger}$
}

\begin{abstract}
This paper investigates the relationship between Bitcoin returns and the frequency of daily abnormal returns over the period from June 2013 to February 2020 using a number of regression techniques and model specifications including standard OLS, weighted least squares (WLS), ARMA and ARMAX models, quantile regressions, Logit and Probit regressions, piecewise linear regressions, and non-linear regressions. Both the in-sample and out-of-sample performance of the various models are compared by means of appropriate selection criteria and statistical tests. These suggest that, on the whole, the piecewise linear models are the best, but in terms of forecasting accuracy they are outperformed by a model that combines the top five to produce "consensus" forecasts. The finding that there exist price patterns that can be exploited to predict future price movements and design profitable trading strategies is of interest both to academics (since it represents evidence against the EMH) and to practitioners (who can use this information for their investment decisions).
\end{abstract}

\section{Introduction}

According to the Efficient Markets Hypothesis (EMH), which remains the dominant paradigm in financial economics, asset prices should follow a random walk, and therefore it should not be possible to design trading strategies that exploit predictable patterns to generate abnormal profits. ${ }^{1}$ However, there is a large body of empirical evidence indicating that there exist various market anomalies resulting in identifiable price patterns such as contrarian and momentum effects; these include calendar anomalies, price over- and under-reactions, other types of anomalies associated with trading volumes, and so on. In the case of the newly emerged cryptocurrency markets, various studies have been carried out which have provided mixed evidence on price predictability. ${ }^{2}$

The current paper contributes to this literature by investigating the relationship between Bitcoin returns and the frequency of daily abnormal returns over the period from June 2013 to February 2020. It extends previous studies by Angelovska and Caporale (et al.) by considering a much wider range of econometric models and approaches over a longer sample, assessing the role of an additional regressor (namely the difference between the frequency of positive and negative abnormal returns), and evaluating the in-sample as well as the out-of-sample

\footnotetext{
* G. M. Caporale (Guglielmo-Maria.Caporale@brunel.ac.uk) is Professor at Brunel University, London, UK.

${ }^{\dagger}$ A. Plastun (o.plastun@uabs.sumdu.edu.ua) is Professor at Sumy State University, Sumy, Ukraine.

$\$$ V. Oliinyk (oliynyk.viktor@gmail.com) is Professor at Sumy State University, Sumy, Ukraine.
} 
performance of the rival models. ${ }^{3,4}$ These include standard OLS, weighted least squares (WLS), ARMA and ARMAX models, quantile regressions, Logit and Probit regressions, piecewise linear regressions, and non-linear regressions.

The remainder of the paper is organised as follows. Section 2 contains a brief review of the relevant literature. Section 3 describes the methodology. Section 4 discusses the empirical results. Section 5 provides some concluding remarks.

\section{Literature Review}

Cryptocurrencies have established themselves in recent years both as an alternative to fiat money and as a tradable asset used for risk-hedging purposes. Various papers have analysed the properties of these newly created markets. For instance, Bartos (2015) and Urquhart (2016) analysed their efficiency; ${ }^{5,6}$ Dwyer (2014) and Carrick (2016) examined volatility in the cryptocurrency market; ${ }^{7,8}$ Corbet et al. (2018) and Cheung et al. (2015) focused on price bubbles; ${ }^{9}, 10$ other market anomalies were explored by Baur et al. (2019), Kurihara and Fukushima (2017), and Caporale and Plastun (2019); ${ }^{11,12,13}$ Bariviera et al. (2017) and Caporale et al. (2018) investigated their persistence and long-memory properties; ${ }^{14,15}$ and Bouri et al. (2019) examined price predictability. ${ }^{16}$

Of particular interest is the issue of whether or not abnormal returns generate stable patterns in price behaviour. This has been a popular topic for investigation since De Bondt and Thaler (1985) developed the overreaction hypothesis. ${ }^{17}$ The evidence is mixed: some papers find price reversals after abnormal price changes, ${ }^{18,19}$ whilst others detect momentum effects. ${ }^{20,21}$ In the specific case of the cryptocurrency markets, Chevapatrakul and Mascia (2019) estimated a quantile autoregressive model and concluded that days with extremely negative returns are likely to be followed by periods characterised by weekly positive returns as Bitcoin prices continue to rise. ${ }^{22}$ Corbet et al. (2019) analysed various technical trading rules in the cryptocurrency market and found significant support for the moving average strategies and also evidence that buy signals generate higher returns than sell signals. ${ }^{23}$ Katsiampa (2019) showed that the volatility of cryptocurrencies responds to news. ${ }^{24}$

Caporale and Plastun (2019) used a variety of statistical tests and trading simulation approaches and found that after one-day abnormal returns price changes in the same direction are bigger than after "normal" days (the so-called momentum effect). ${ }^{4}$ Caporale et al. (2019) provided evidence on the role played by the frequency of overreactions. ${ }^{4}$ Qing et al. (2019) applied DFA and MF-DFA methods and found momentum effects in Bitcoin and Ethereum prices after abnormal returns. ${ }^{25}$ Momentum effects were also detected by Panagiotis et al. (2019) and Yukun and Tsyvinski (2019). ${ }^{26,27}$ The present study extends the previous one by Caporale et al. (2019) by using different methods (quantile regressions, Logit and Probit regressions, piecewise linear regressions, and non-linear regressions are used in this paper instead of the VAR and ARIMA models estimated by Caporale et al., 2019), examining a longer sample (up to 2020), including different variables (the difference between the frequency of positive and negative abnormal returns parameter introduced in this paper), and evaluating both the in-sample and out-of-sample performance of the estimated models (using various criteria such as AIC, BIC, MAE, Theil's statistic, etc.). ${ }^{4}$ 


\section{Methodology}

The selected sample includes daily and monthly Bitcoin data over the period June 2013February 2020. The data source is CoinMarketCap. ${ }^{28}$ For forecasting purposes, two subsamples are created, namely 1 June 2013-30 December 2018 and 1 January 2019-28 February 2020 at the daily frequency, and June 2013-December 2018 and January 2019-February 2020 at the monthly frequency; various models are estimated over the first subsample, forecasts are then generated in each case for the second subsample using the estimated parameters, and their accuracy is evaluated by means of various statistical criteria.

As a first step, abnormal returns are computed using the daily series. The dynamic trigger approach is based on relative values, specifically abnormal returns are defined on the basis of the number of standard deviations to be added to average returns. ${ }^{29}$ By contrast, the static approach requires setting a threshold; for example, Bremer and Sweeney (1991) use a 10\% price change as a criterion for abnormal returns. ${ }^{18}$ Caporale and Plastun (2019) compared the suitability of these methods in the case of cryptocurrency markets and concluded that the latter is preferable. ${ }^{13}$

An additional argument in favour of the static approach is the presence of fat tails in the distribution of Bitcoin prices (see Appendix A, Figure A.1) which means that a dynamic trigger approach, which is based on a standard normal distribution, might provide misleading results. This is confirmed by Caporale and Plastun (2019) who showed that the correlation between the frequency of abnormal returns (based on the two aforementioned methods for abnormal returns detection in turn) and the VIX index dynamics is much higher when using the static approach, which is crucial for the purposes of our analysis (i.e. price prediction) ${ }^{30}$ specifically, the dynamic trigger approach produces a correlation coefficient of 0.12 whilst the static one yields a coefficient equal to 0.81 . Therefore, the static approach will be applied here.

Returns are defined as:

$$
R_{t}=\ln \left(P_{t}\right)-\ln \left(P_{t-1}\right)
$$

where $R_{t}$ stands for returns, and $P_{t}$ and $P_{t-1}$ are the close prices of the current and previous day.

To analyse their frequency, distribution histograms are created. Values $10 \%$ above or below those of the population are plotted. Thresholds are then obtained for both positive and negative abnormal returns, and periods can be identified when returns were above or equal to the threshold. Such a procedure generates a data set for daily abnormal returns. We then calculate their frequency, namely the cumulative number of positive / negative abnormal returns detected during a month (which is a time-varying parameter changing on a daily basis) and use the endof-the-month values for the following regression analysis.

Next the data set for the frequency of abnormal returns is divided into three subsets including, respectively, the frequency of negative and positive abnormal returns, and their difference, known as delta. The relationship between the frequency of one-day abnormal returns and Bitcoin returns is investigated by using a number of regression techniques and model specifications including standard OLS, weighted least squares (WLS), ARIMA and ARMAX 
models, quantile regressions, Logit and Probit regressions, piecewise linear regressions, and non-linear regressions.

The specification of the standard OLS regression is the following (2):

$$
Y_{t}=a_{0}+a_{1} F_{t}^{+}+a_{2} F_{t}^{-}+\varepsilon_{t}
$$

where $Y_{t}-$ Bitcoin log returns in period (month) $t$;

$\mathrm{a}_{0}-$ Bitcoin mean log return;

$a_{1}\left(a_{2}\right)$ - coefficients on the frequency of positive and negative one-day abnormal price, respectively;

$\mathrm{F}_{\mathrm{t}}^{+}\left(F_{t}^{-}\right)$- the frequency of positive (negative) one-day abnormal price days during period $t$

$\varepsilon_{t}-$ random error term at time $t$.

An OLS regression including the single parameter Delta $\left(\right.$ Delta $\left.=F^{+}-F^{-}\right)$instead of $\mathrm{F}_{\mathrm{t}}^{+}$ $\left(F_{t}^{-}\right)$is also run:

$$
Y_{t}=a_{0}+a_{1} \text { Delta }_{t}+\varepsilon_{t}
$$

The size, sign, and statistical significance of the estimated coefficients provide information about the possible effects of the frequency of daily abnormal returns on Bitcoin log returns. The weighted least squares regressions are similar, but instead of treating all observations equally they are weighted to increase the accuracy of the estimates.

To obtain further evidence an $\operatorname{ARMA}(p, q)$ model is also estimated (4):

$$
Y_{t}=a_{0}+\sum_{i=1}^{p} \Psi_{t-i} Y_{t-1}+\sum_{i=0}^{q} \theta_{t-i} \varepsilon_{t-i}
$$

where $Y_{t}-$ Bitcoin $\log$ returns in month $t$;

$a_{0}$ - constant;

$\Psi_{t-i} ; \theta_{t-i}-$ coefficients, the lagged log returns and random error terms respectively;

$\varepsilon_{\mathrm{t}}-$ random error term at time $t$;

This is a special case of an $\operatorname{ARIMA}(p, d, q)$ specification with $d=0$, which is appropriate in our case since all series are stationary, as indicated by a variety of unity root tests which imply that differencing is not required (the test results are not reported for reasons of space but are available from the authors upon request).

Next, in order to improve the basic $\operatorname{ARMA}(p, q)$ specification, exogenous variables are added, namely the frequency of negative and positive one-day abnormal returns in (5) and Delta in (6), to obtain the following $\operatorname{ARMAX}(\mathrm{p}, \mathrm{q}, 2)$ and $\operatorname{ARMAX}(\mathrm{p}, \mathrm{q}, 1)$ models: 


$$
\begin{aligned}
& Y_{t}=a_{0}+\sum_{i=1}^{p} \Psi_{t-i} Y_{t-1}+\sum_{i=0}^{q} \theta_{t-i} \varepsilon_{t-i}+a_{1} F_{t}^{+}+a_{2} F_{t}^{-} \\
& Y_{t}=a_{0}+\sum_{i=1}^{p} \Psi_{t-i} Y_{t-1}+\sum_{i=0}^{q} \theta_{t-i} \varepsilon_{t-i}+a_{1} \text { Delta }_{t}
\end{aligned}
$$

A non-parametric method not requiring normality is also used; specifically, quantile regressions are run to estimate the conditional median instead of the conditional mean. More precisely, the quantile regression model for the $\tau$-th quantile is specified as follows (7-8):

$$
\begin{aligned}
& Y_{t}=a_{0}(\tau)+a_{1}(\tau) F_{t}^{+}+a_{2}(\tau) F_{t}^{-}+\varepsilon_{t}(\tau) \\
& Y_{t}=a_{0}(\tau)+a_{1}(\tau) \text { Delta } a_{t}+\varepsilon_{t}(\tau)
\end{aligned}
$$

where $\tau$ - the $\tau$-th quantile and $\tau \in(0,1)$;

Next, Probit and Logit regression models are estimated. These are specific cases of binary choice models that provide estimates of the probability that the dependent variable will take the value 1. In a Logit regression, it is assumed that $P\{y=1 \mid x\}=f(z)$, where $f(z)=\frac{1}{1+\exp (-z)}$ is the logistic function, and the parameter $z$ is obtained from the regression (9-10):

$$
\begin{aligned}
& z_{t}=a_{0}+a_{1} F_{t}^{+}+a_{2} F_{t}^{-}+\varepsilon_{t} \\
& z_{t}=a_{0}+a_{1} \text { Delta }_{t}+\varepsilon_{t}
\end{aligned}
$$

where $z_{t}$ is a binary variable equal to 1 if the return in month $t$ increased compared to day $t$ 1 , and 0 otherwise.

To allow for the possibility that the linear relationship between the dependent variable and the independent ones changes between subsamples a piecewise linear regression is then run to obtain estimates of the coefficients of interest before and after a given breakpoint, specifically: 


$$
\begin{aligned}
& Y=\left\{\frac{a_{0}+a_{1} F^{+}+a_{2} F^{-}+\varepsilon_{1}, Y \leq C_{1}}{b_{0}+b_{1} F^{+}+b_{2} F^{-}+\varepsilon_{2}, Y>C_{1}}\right\} \\
& Y=\left\{\frac{a_{0}+a_{1} \text { Delta }+\varepsilon_{1}, \text { Delta } \leq C_{2}}{a_{0}+a_{1} \text { Delta }+\varepsilon_{2}, \text { Delta }>C_{2}}\right\}
\end{aligned}
$$

where $C_{1}$ and $C_{2}$ are the breakpoints.

Possible non-linearities are also considered by estimating a non-linear regression model (NLS) such as:

$$
Y=f\left(x_{i}\right)(i=\overline{1, n})
$$

where $Y$-dependent variable;

$x_{i}$ - regressors.

Specifically, we run the following regression:

$$
Y=a_{0}+b\left(F^{+}\right)^{p}+c\left(F^{-}\right)^{q}+\varepsilon
$$

where $a_{0}, b, c, p, q$ are the model parameters.

Information criteria, namely $\mathrm{AIC}$ and $\mathrm{BIC},{ }^{31,32}$ are used to select the best model specification for Bitcoin log returns. To compare the forecasting performance of different models, various measures such as the Mean Absolute Error (MAE) and Theil's statistic are computed instead.

\section{Empirical Results}

As a first step, thresholds are calculated by analysing the frequency distribution of log returns to detect abnormal returns (see Appendix A, Table A.1 and Figure A.1). As can be seen, two symmetric fat tails are present in the distribution for log returns: -0.04 for negative returns and 0.05 for positive ones; these are then used as the thresholds to detect negative and positive abnormal returns respectively.

Next we carry out correlation analysis for negative and positive abnormal returns and Bitcoin log returns as in Caporale et al. (2019). ${ }^{4}$ Specifically, we compute the correlation between Delta and Bitcoin log returns, which is equal to 0.87 , and to make sure that there is no need to shift the data we calculate the cross-correlations at the time intervals $t$ and $t+i$, where $I=\{-10, \ldots, 10\}$. Appendix D, Figure D.1 shows them over the whole sample period for 
different leads and lags. The highest coefficient corresponds to lag length zero, which means that there is no need to shift the data.

The OLS and WLS regression results are reported in Appendix E, Table E.1. Models 1 and 2 are the standard OLS regressions given by (2) and (3), whilst models 1.1 and 2.1 are the WLS ones, where the weights are the inverse of the standard error for each observation used.

As can be seen the two sets of estimates are very similar. The selected specification, on the basis of the R-squared for the whole model, the p-values for the individual estimated coefficients as well as AIC and BIC criteria, is the following:

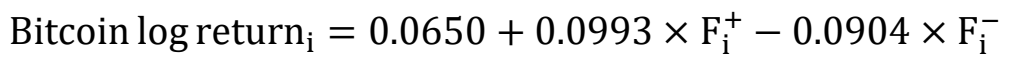

which implies a significant positive (negative) relationship between Bitcoin log returns and the frequency of positive (negative) abnormal returns. Any difference between the actual and estimated values suggests that Bitcoin is over- or under-valued, and therefore that it should be sold or bought till the observed difference disappears, at which stage positions should be closed.

The estimates from the selected ARMA(p,q) models on the basis of the AIC and BIC information criteria, namely $\operatorname{ARMA}(2,2)$ and $\operatorname{ARMA}(3,3)$, are presented in Table F.1. As can be seen, although most coefficients are significant, the explanatory power of these models is rather low.

To establish whether it can be improved by taking into account information about the frequency of abnormal returns, ARMAX models (4) are estimated. First $F_{t}^{+}$(the frequency of positive abnormal returns) and $F_{t}^{-}$(the frequency of negative abnormal returns) are added as regressors. The estimated parameters are reported in Appendix G, Table G.1. Model 6 and 7 correspond respectively to Model 3 and 4 with the frequency of negative and positive abnormal returns as additional regressors. They outperform Model 5, namely the best ARMAX specification with $p=1$. Table G.2 reports instead the estimates from the ARMAX models with Delta as a regressor.

As can be seen all coefficients in Tables G.1 and G.2 are statistically significant. The best model on the basis of the AIC and BIC criteria is the one with Delta as a regressor. The R2 indicates that the ARMAX $(3,3,1)$ is the most adequate model (Model 10).

Appendix H, Tables H.1, H.2, and H.3 report the estimates from the quantile regression models with quantiles equal to $0.4,0.5$, and 0.6 respectively, where the 0.5 quantile corresponds to the regression using the median.

In Models 11, 13, and 15 the regressors are the frequency of negative and positive daily abnormal returns, whilst in Models 12, 14, and 16, Delta is the independent variable. In the case of the quantile regression with $\mathrm{Q}=0.5$ Model 13 is the most adequate according to AIC.

The Logit and Probit regression results are presented in Appendix I, Table I.1. As a selection criterion, the percentage of correctly predicted cases is used; this suggests that the best specification is Model 19 which includes the frequency of negative and positive daily abnormal returns.

Appendix I, Table I. 2 shows the piecewise linear regression results. Model 2 includes the frequency of negative and positive daily abnormal returns and $C_{1}=0$ is used as a breakpoint: for $C_{1}>0$ Bitcoin returns are positive, otherwise $\left(C_{1}<0\right)$ they are negative. Model 22 
includes instead the Delta parameter with $C_{2}=0$ as the breakpoint. Both $R^{2}$ and AIC imply that Model 21 should be preferred.

Non-linear models of two types are estimated next: non-linear in the regressors (but linear in the parameters) and in the parameters respectively. In the first case, the model can be transformed into a linear one by replacing the variables, and then the parameters can be estimated using OLS. In the second case, iterative procedures have to be used instead.

The first type can be formulated as follows (16):

$$
Y=a_{0}+\sum_{i-1}^{n} a_{i} x_{i}+\varepsilon
$$

where $Y_{t}-$ Bitcoin log returns;

$a_{0}$ - constant;

$a_{i}$ - coefficients on the $i$-th regressors;

$x_{i}$ - regressors;

$\varepsilon-$ random error.

The modified variables (selected after some experimentation) are the following:

$$
\begin{aligned}
& x_{1}=\text { Delta } ; x_{2}=F^{+} \times \text {Delta } ; x_{3}=\tan \left(F^{+}\right) \times\left(F^{+}+F^{-}\right) ; x_{4}=\sin \left(F^{-}\right) \times\left(F^{+}\right)^{2} ; \\
& x_{5}=F^{-} \times\left(F^{+}+F^{-}\right) ; x_{6}=\text { Delta } \times F^{-} \times\left(F^{+}+F^{-}\right)
\end{aligned}
$$

Appendix J, Table J.1 reports the corresponding parameter estimates. As can be seen both models 23 and 24 have statistically significant coefficients, but according to $R^{2}$ and AIC Model 24 should be preferred.

The second type of non-linear model incorporates a new variable, namely $x_{6}=x_{1} x_{5}$, and is specified as follows:

$$
Y=a_{0}+b\left(F^{+}\right)^{p}+c\left(F^{-}\right)^{q}+\sum_{i=1}^{n} a_{i} x_{i}+\varepsilon
$$

The corresponding estimates are shown in Appendix J, Table J.2. All coefficients are statistically significant. Model 27 is the most data congruent:

$$
\begin{aligned}
Y=0.0618+ & 0.0418 \times\left(F^{+}\right)^{1.4688}-0.0472 \times\left(F^{-}\right)^{1.4018}+0.0031 \\
& \times \tan \left(F^{+}\right) \\
& \times \tan \left(F^{+}+F^{-}\right)-0.0036 \\
& \times \sin \left(F^{+}\right) \times\left(F^{-}\right)^{2}-0.0006 \times \text { Delta } \times F^{-} \times\left(F^{+}+F^{-}\right)
\end{aligned}
$$

Table 1 reports the ranking of the top five models (of the 29 considered) according to the AIC criterion. As can be seen the non-linear and piecewise linear regressions appear to be the most data congruent. 
LEDGER VOL 6 (2021) 17-41

Table 1: Ranking of the models based on their in-sample performance (June 2013-December 2018)

$\begin{array}{lcccr}\text { Rank } & \text { Model \# } & \text { AIC } & \boldsymbol{R}^{\mathbf{2}} & \text { Standard Error } \\ \mathbf{1} & 24 & -98.7446 & 0.8783 & 0.1109 \\ \mathbf{2} & 27 & -96.4904 & 0.8814 & 0.1113 \\ \mathbf{3} & 26 & -94.9453 & 0.7919 & 0.1126 \\ \mathbf{4} & 21 & -94.6726 & 0.8707 & 0.1144 \\ \mathbf{5} & 22 & -71.8255 & 0.8012 & 0.1385\end{array}$

This table presents a ranking of the models based on their in-sample performance. The first column reports the rank, the second column shows the model number, the third reports the AIC values, the fourth the $R^{2}$ values and the fifth the standard errors.

Next, we use the estimated models to generate forecasts over the period January 2019February 2020; both predicted and actual values are reported in Appendix B, Table B.1. Appendix C, Table C.1 presents the following measures of their forecasting accuracy: the Root Mean Square Error (RMSE), the Mean Absolute Error (MAE), the Mean Percentage Error (MPE), the Mean Absolute Percentage Error (MAPE), and Theil's U. Table 2 ranks the rival models in terms of their forecasting performance using the Mean Absolute Error (MAE) and Theil's U criteria.

Table 2: Ranking of the models on the basis of the MAE and Theil's U criteria

$\begin{array}{lccccr}\text { Rank } & \text { Model \# } & \text { MAE } & \text { Rank } & \text { Model \# } & \text { Theil's U } \\ \mathbf{1} & 21 & 0.0796 & 1 & 21 & 0.5485 \\ \mathbf{2} & 22 & 0.0889 & 2 & 22 & 0.6600 \\ \mathbf{3} & 23 & 0.0949 & 3 & 15 & 0.6639 \\ \mathbf{4} & 25 & 0.0958 & 4 & 13 & 0.6675 \\ \mathbf{5} & 2.1 & 0.0997 & 5 & 2.1 & 0.6767\end{array}$

This table presents ranking of the models based on their out-of-sample performance. The first and the fourth column report the corresponding rank, the second and the fourth column show the model number, the third and the sixth the MAE and Theil's U values.

It can be seen that Models 21 and 22 (piecewise linear regressions) are still in the top five specifications, and therefore the overall evidence based on both in-sample and out-of-sample performance suggests that they are the best models for Bitcoin returns.

Finally, we evaluate the accuracy of the "consensus" forecasts produced by a model that combines the top five selected above and therefore is specified as follows:

$$
\begin{aligned}
Y=0.0754+ & 7.2578 \text { Model } 2.1-5.9761 \text { Model } 14+1.6021 \text { Model } 22 \\
& -10.3993 \text { Model } 24+8.6068 \text { Model } 26 \\
R^{2}=0.7211, F= & 4.1356(0.0374)
\end{aligned}
$$


where the weights have been estimated by running a standard multiple linear regression. As can be seen from the forecasting accuracy measures reported in Appendix C, Table C.1, this model outperforms all the individual ones.

\section{Conclusions}

This paper carries out a comprehensive examination of the role played by the frequency of daily abnormal returns in driving Bitcoin returns over the period from June 2013 to February 2020. It extends the work of Caporale et al. (2019) by considering a much wider range of models over a longer sample period, ${ }^{4}$ exploring the role of the difference between the frequency of positive and negative abnormal returns as well, and assessing the forecasting accuracy of the rival models in addition to their in-sample performance. The results indicate that, if one takes into account both in-sample and out-of-sample performance, piecewise linear models are the best for Bitcoin returns. However, in terms of forecasting accuracy they are outperformed by a model that combines the top five to produce "consensus" forecasts.

On the whole, the results suggest that the frequency of abnormal returns is informative about price dynamics in the cryptocurrency market. They are of interest to both practitioners (who can use this information for their investment decisions) and academics (since they represent evidence again the EMH). More specifically, they imply that investors and traders can use the frequency of abnormal returns for the purpose of predicting prices and designing profitable trading strategies in the cryptocurrency market. For example, the number of days with negative and positive abnormal returns during a month can be used to predict Bitcoin returns - the models estimated in this paper provide benchmark values against which buying/selling decisions can be made. The detected lack of efficiency in the Bitcoin market also represents an interesting issue for academics to investigate in the future by empirically testing alternative explanations and/or developing new models based on the more realistic assumptions of bounded rationality and learning.

\section{Acknowledgement}

Alex Plastun gratefully acknowledges financial support from the Ministry of Education and Science of Ukraine (0121U100473).

\section{Author Contributions}

All authors contributed equally to all aspects of the paper.

\section{Notes and References}

${ }^{1}$ Fama, E. F. “The Behavior of Stock-Market Prices.” The Journal of Business 38 34-105 (1965)

https://www.jstor.org/stable/2350752. 
${ }^{2}$ Including but not limited to Gil-Alana, L.A., Cunado, J., Perez de Gracia, F. "Salient Features of Dependence in Daily US Stock Market Indices." Physica A: Statistical Mechanics and its Applications 392.15 3198-3212 (2013) https://doi.org/10.1016/j.physa.2013 .03.040; Ciaian, P., Rajcaniova, M., Kancs, D.A. "The Economics of Bitcoin Price Formation." Applied Economics 48.19 1799-1815 (2016) https://doi.org/10.1080/ 00036846.2015 .1109038 ; Balcilar, M., Bouri, E., Gupta, R., Rouband, D. "Can Volume Predict Bitcoin Returns and Volatility? A Quantiles Based Approach.” Economic Modeling 64 74-81 (2017) https://doi.org/10.1016/j.econmod.2017.03.019; Khuntia, S., Pattanayak, J. "Adaptive Market Hypothesis and Evolving Predictability of Bitcoin." Economic Letters 167 26-28 (2018) https://doi.org/10.1016/j.econlet.2018.03.005; and AlYahyaee, K., Rehman, M., Mensi, W., Al-Jarrah, I. "Can Uncertainty Indices Predict Bitcoin Prices? A Revisited Analysis Using Partial and Multivariate Wavelet Approaches." The North American Journal of Economics and Finance 49 47-56 (2019) https://doi.org/10.1016/j.najef.2019.03.019.

${ }^{3}$ Angelovska, J. "Large Share Price Movements, Reasons and Market Reaction.” Management 21 1-17 (2016) https: / /www. ceeol.com/search/article-detail?id=573234.

${ }^{4}$ Caporale, G.M., Plastun, A. Oliinyk, V. "Bitcoin Fluctuations and the Frequency of Price Overreactions." Financial Markets and Portfolio Management 33.2 109-131 (2019) https://doi.org/10.1007/s11408-019-00332-5.

${ }^{5}$ Bartos, J. "Does Bitcoin Follow the Hypothesis of Efficient Market?" International Journal of Economic Sciences IV.2 10-23 (2015) https://doi.org/10.20472/ES.2015.4.2.002.

${ }^{6}$ Urquhart, A. “The Inefficiency of Bitcoin.” Economics Letters 148 80-82 (2016) https://doi.org/10.1016/j.econlet.2016.09.019.

${ }^{7}$ Dwyer, G. P. "The Economics of Bitcoin and Similar Private Digital Currencies." Journal of Financial Stability 17 81-91 (2014) https://doi.org/10.1016/j.jfs.2014.11.006.

${ }^{8}$ Carrick, J. "Bitcoin as a Complement to Emerging Market Currencies." Emerging Markets Finance and Trade 52, 2321-2334 (2016) https://doi.org/10.1080/ 1540496X.2016.1193002.

${ }^{9}$ Corbet, S., Lucey, B., Yarovaya, L. "Datestamping the Bitcoin and Ethereum Bubbles." Finance Research Letters 26 81-88 (2018) https://doi.org/10.1016/ j.frl.2017.12.006.

${ }^{10}$ Cheung, A., Roca, E., Su, J.-J. "Crypto-Currency Bubbles: An Application of the PhillipsShi-Yu (2013) Methodology on Mt. Gox Bitcoin Prices." Applied Economics 47 2348-2358 (2015) https://doi.org/10.1080/00036846.2015.1005827. 
${ }^{11}$ Baur, Dirk G., Cahill, D., Godfrey, K., Liu, Z. "Bitcoin Time-of-Day, Day-of-Week and Month-of-Year Effects in Returns and Trading Volume." Finance Research Letters 31 78-92 (2019) https://doi.org/10.1016/j.frl.2019.04.023.

${ }^{12}$ Kurihara, Y., Fukushima, A. "The Market Efficiency of Bitcoin: A Weekly Anomaly Perspective." Journal of Applied Finance \& Banking 7.3 57-64 (2017) https://ideas.repec.org/a/spt/apfiba/v7y2017i3f7_3_4.html.

${ }^{13}$ Caporale, G., Plastun, A. "Price Overreactions in the Cryptocurrency Market." Journal of Economic Studies 46.5 1137-1155 (2019) http: //doi.org/10.1108/JES-09-2018-0310.

${ }^{14}$ Bariviera, A. F. “The Inefficiency of Bitcoin Revisited: A Dynamic Approach.” Economics Letters 161 1-4 (2017) https://doi.org/10.1016/j.econlet.2017.09.013.

${ }^{15}$ Caporale, G. M., Gil-Alana, L., Plastun, A. "Persistence in the Cryptocurrency Market." Research in International Business and Finance 46 141-14 (2018) https://doi.org/10.1016/j.ribaf.2018.01.002.

${ }^{16}$ Bouri, E., Lau, C. K., Lucey, B., Roubaud, D. "Trading Volume and the Predictability of Return and Volatility in the Cryptocurrency Market." Finance Research Letters 29 340-346 (2019) https://doi.org/10.1016/j.frl.2018.08.015.

${ }^{17}$ De Bondt, W., Thaler R. "Does the Stock Market Overreact?" Journal of Finance 40793 808 (1985) https://doi.org/10.1111/j.1540-6261.1985.tb05004.x.

${ }^{18}$ Bremer, M., Sweeney, R. “The Reversal of Large Stock Price Decreases.” Journal of Finance 46 747-754 (1991) https: //doi.org/10.2307/2328846.

${ }^{19}$ Larson, S., Madura, J. "Overreaction and Underreaction in the Foreign Exchange Market." Global Finance Journal 12.2 153-177 (2001) https://doi.org/10.1016/S1044$0283(01) 00026-6$.

${ }^{20}$ Schnusenberg, O., Madura, J. “Do US Stock Market Indexes Over- or Under-React?” Journal of Financial Research 24.2 179-204 (2001) https://doi.org/10.1111/j.14756803.2001. tb00764.x.

${ }^{21}$ Lasfer, M. A., Melnik, A., Thomas, D. C. "Short-Term Reaction of Stock Markets in Stressful Circumstances." Journal of Banking \& Finance 27.10 1959-1977 (2003) https://doi.org/10.1016/S0378-4266(02)00313-8.

${ }^{22}$ Chevapatrakul, T., Mascia, D. "Detecting Overreaction in the Bitcoin Market: A Quantile Autoregression Approach.” Finance Research Letters 30 371-377 (2019) https://doi.org/10.1016/j.frl.2018.11.004. 
${ }^{23}$ Corbet, Shaen, Eraslan, V., Lucey, B., Sensoy, A. "The Effectiveness of Technical Trading Rules in Cryptocurrency Markets." Finance Research Letters 31 32-37 (2019) https://doi.org/10.1016/j.frl.2019.04.027.

${ }^{24}$ Katsiampa, P. "An Empirical Investigation of Volatility Dynamics in the Cryptocurrency Market." Research in International Business and Finance 50 322-335 (2019)

https://doi.org/10.1016/j.ribaf.2019.06.004.

${ }^{25}$ Qing, C., Xinyuan, L., Xiaowu, Z. "Cryptocurrency Momentum Effect: DFA and MF-DFA Analysis." Physica A: Statistical Mechanics and its Applications 526 (2019) https://doi.org/10.1016/j.physa.2019.04.083.

${ }^{26}$ Panagiotis, T., Renatas, K., Bayasgalan, T. "Momentum Trading in Cryptocurrencies: ShortTerm Returns and Diversification Benefits." Economics Letters (2019) https://doi.org/10.1016/j.econlet.2019.108728.

${ }^{27}$ Yukun, L., Tsyvinski, A. "Risks and Returns of Cryptocurrency." Society for Economic $\begin{array}{lllll}\text { Dynamic } & 2019 & \text { Meeting } & \text { Papers } & 160\end{array}$ https://ideas.repec.org/p/red/sed019/160.html.

${ }^{28}$ https://coinmarketcap.com/currencies/bitcoin/.

${ }^{29}$ Wong, M. "Abnormal Stock Returns Following Large One-day Advances and Declines: Evidence from Asian-Pacific Markets." Financial Engineering and Japanese Markets 4 71-177 (1997) https://doi.org/10.1023/A:1009625931727.

${ }^{30}$ Caporale, G., Plastun, A. "On Stock Price Overreactions: Frequency, Seasonality and Information Content." Journal of Applied Economics 22.1 602-621 (2019) https://doi.org/10.1080/15140326.2019.1692509.

${ }^{31}$ Akaike, H. "A New Look at the Statistical Model Identification." IEEE Transactions on Automatic Control 19.6 716-723 (1974) https://doi.org/10.1109/TAC.1974.1100705.

${ }^{32}$ Schwarz, G. E. "Estimating the Dimension of a Model." Annals of Statistics 6.2 461-464 (1978) https://doi.org/10.1214/aos/1176344136. 


\section{Appendix A}

Table A.1: Frequency distribution of Bitcoin, May 2013-February 2020

\begin{tabular}{cc} 
Plot & Frequency \\
$<<-\mathbf{0 . 0 4}$ & 242 \\
$\mathbf{- 0 . 0 3}$ & 102 \\
$\mathbf{- 0 . 0 2}$ & 140 \\
$\mathbf{- 0 . 0 1}$ & 220 \\
$\mathbf{0}$ & 462 \\
$\mathbf{0 . 0 1}$ & 481 \\
$\mathbf{0 . 0 2}$ & 282 \\
$\mathbf{0 . 0 3}$ & 184 \\
$\mathbf{0 . 0 4}$ & 118 \\
$\mathbf{0 . 0 5}$ & 85 \\
$>\mathbf{0 . 0 5}$ & 204 \\
\hline
\end{tabular}

This table presents estimates of the frequency distribution for Bitcoin log returns over the period 01.05.2013-28.02.2020. The first column reports the values for Bitcoin log returns, the second column the corresponding frequency.

Figure A.1: Frequency distribution of Bitcoin, May 2013-February 2020

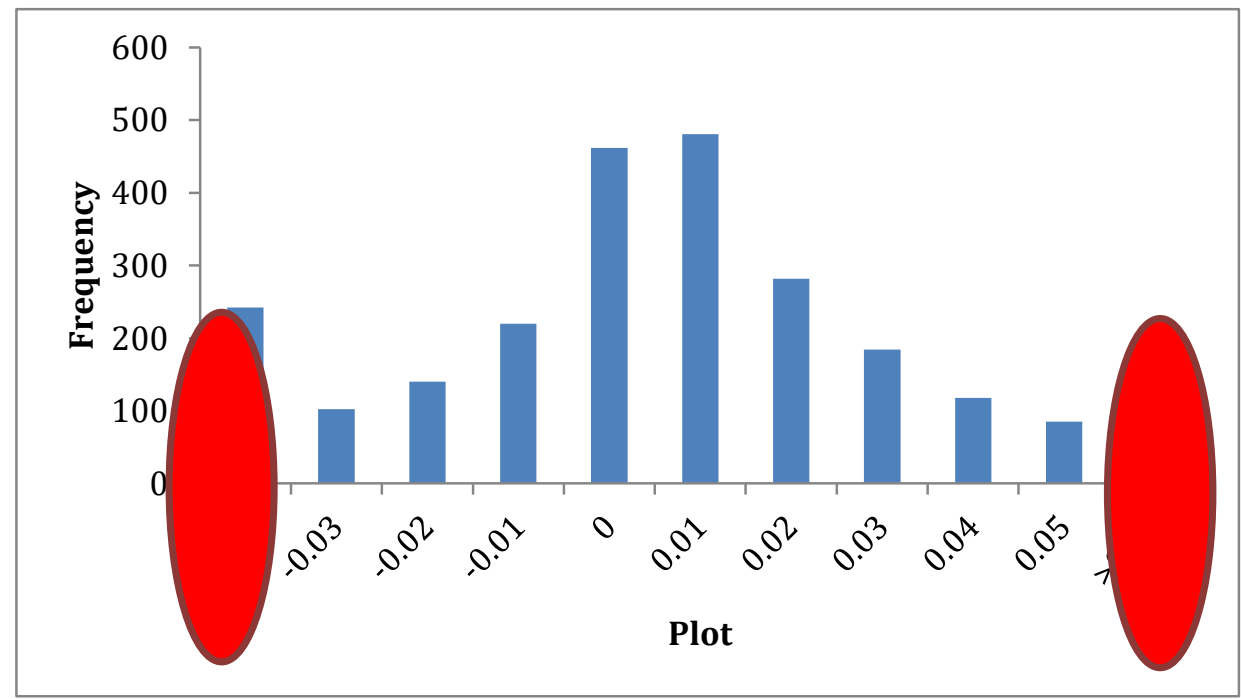

This figure presents the frequency distribution estimates for Bitcoin log returns over the period 1 May 201328 February 2020. The plot size is displayed on the $\mathrm{x}$ axis; the number of log returns fitting the corresponding plot is displayed on the $y$ axis. 


\section{Appendix B}

Table B.1: Predicted vs actual values over the period January 2019-February 2020

\begin{tabular}{|c|c|c|c|c|c|c|c|c|c|c|c|c|c|c|}
\hline Period & Jan 2019 & Feb 2019 & Mar 2019 & Apr 2019 & May 2019 & Jun 2019 & Jul 2019 & Aug 2019 & Sep 2019 & Oct 2019 & Nov 2019 & Dec 2019 & Jan 2020 & Feb 2020 \\
\hline Actual value & -0.0791 & 0.1086 & 0.0629 & 0.2649 & 0.4715 & 0.2323 & -0.07 & -0.0461 & -0.1494 & 0.1036 & -0.195 & -0.0509 & 0.2622 & -0.0837 \\
\hline Model 1 & 0.0901 & 0.1855 & 0.0901 & -0.0052 & 0.2808 & 0.2808 & -0.1006 & -0.196 & -0.0052 & 0.1855 & -0.2913 & 0.0901 & 0.2808 & -0.196 \\
\hline Model 2 & 0.074 & 0.1734 & 0.0651 & -0.0165 & 0.2817 & 0.2995 & -0.0803 & -0.1886 & -0.0165 & 0.1734 & -0.2968 & 0.074 & 0.2639 & -0.2064 \\
\hline Model 3 & -0.1279 & 0.0685 & 0.19 & 0.0874 & -0.0381 & -0.0061 & 0.0977 & 0.1102 & 0.038 & 0.0036 & 0.0449 & 0.0847 & 0.0681 & 0.0329 \\
\hline Model 4 & -0.0823 & 0.0201 & 0.1232 & 0.1465 & 0.0429 & -0.0301 & -0.0044 & 0.0882 & 0.1236 & 0.0717 & 0.0005 & -0.0014 & 0.0584 & 0.1033 \\
\hline Model 5 & 0.1021 & 0.2006 & 0.0929 & 0.0058 & 0.3038 & 0.3166 & -0.0693 & -0.1768 & 0.0011 & 0.1927 & -0.2858 & 0.0915 & 0.2833 & -0.1951 \\
\hline Model 6 & 0.1515 & 0.1458 & 0.0518 & 0.0285 & 0.2411 & 0.3314 & -0.0836 & -0.2201 & 0.0113 & 0.159 & -0.3041 & 0.0874 & 0.2551 & -0.2 \\
\hline Model 7 & 0.1093 & 0.2075 & 0.0316 & -0.0498 & 0.2549 & 0.329 & -0.044 & -0.1711 & -0.0482 & 0.1427 & -0.2923 & 0.1068 & 0.2839 & -0.2041 \\
\hline Model 8 & 0.1187 & 0.2138 & 0.1157 & 0.0177 & 0.3065 & 0.3053 & -0.0825 & -0.1803 & 0.012 & 0.2044 & -0.2798 & 0.106 & 0.2985 & -0.1856 \\
\hline Model 9 & 0.1681 & 0.1514 & 0.0824 & 0.0329 & 0.2439 & 0.3138 & -0.1054 & -0.2224 & 0.0176 & 0.1727 & -0.2984 & 0.1 & 0.2745 & -0.1929 \\
\hline Model 10 & 0.1951 & 0.1855 & 0.1186 & 0.0563 & 0.276 & 0.3458 & -0.0868 & -0.1971 & 0.0398 & 0.1929 & -0.2766 & 0.1172 & 0.2962 & -0.1748 \\
\hline Model 11 & 0.0402 & 0.1368 & 0.0257 & -0.0419 & 0.2479 & 0.2769 & -0.0807 & -0.1918 & -0.0419 & 0.1368 & -0.3029 & 0.0402 & 0.219 & -0.2207 \\
\hline Model 12 & 0.049 & 0.1335 & 0.049 & -0.0356 & 0.218 & 0.218 & -0.1201 & -0.2046 & -0.0356 & 0.1335 & -0.2892 & 0.049 & 0.218 & -0.2046 \\
\hline Model 13 & 0.0621 & 0.1632 & 0.0414 & -0.0183 & 0.2849 & 0.3263 & -0.0366 & -0.1583 & -0.0183 & 0.1632 & -0.2801 & 0.0621 & 0.2436 & -0.1997 \\
\hline Model 14 & 0.081 & 0.17 & 0.081 & -0.0079 & 0.259 & 0.259 & -0.0969 & -0.1859 & -0.0079 & 0.17 & -0.2748 & 0.081 & 0.259 & -0.1859 \\
\hline Model 15 & 0.0813 & 0.1873 & 0.0578 & -0.0013 & 0.3168 & 0.3636 & -0.0136 & -0.143 & -0.0013 & 0.1873 & -0.2725 & 0.0813 & 0.2699 & -0.1899 \\
\hline Model 16 & 0.1331 & 0.2218 & 0.1331 & 0.0443 & 0.3106 & 0.3106 & -0.0444 & -0.1332 & 0.0443 & 0.2218 & -0.222 & 0.1331 & 0.3106 & -0.1332 \\
\hline Model 21 & -0.0317 & 0.2072 & 0.0911 & 0.0224 & 0.3233 & 0.3549 & -0.0967 & -0.1369 & -0.0675 & 0.2072 & -0.1771 & -0.0317 & 0.2917 & -0.1413 \\
\hline Model 22 & 0.0404 & 0.1575 & 0.0404 & -0.0262 & 0.2745 & 0.2745 & -0.0927 & -0.1593 & -0.0262 & 0.1575 & -0.2259 & 0.0404 & 0.2745 & -0.1593 \\
\hline Model 23 & 0.0923 & 0.1523 & 0.0854 & 0.0172 & 0.2755 & 0.2655 & -0.0638 & -0.1929 & 0.0172 & 0.1523 & -0.2168 & 0.0923 & 0.2386 & -0.1413 \\
\hline Model 24 & 0.0678 & 0.1159 & 0.0589 & -0.0027 & 0.2386 & 0.4327 & -0.0115 & -0.1891 & -0.0027 & 0.1159 & -0.2147 & 0.0678 & 0.2187 & -0.1502 \\
\hline Model 25 & 0.0662 & 0.1389 & 0.074 & -0.0066 & 0.242 & 0.2821 & -0.0979 & -0.1838 & -0.0066 & 0.1389 & -0.2206 & 0.0662 & 0.1978 & -0.1369 \\
\hline Model 26 & 0.0608 & 0.1046 & 0.0659 & -0.0058 & 0.2375 & 0.441 & -0.0089 & -0.194 & -0.0058 & 0.1046 & -0.2001 & 0.0608 & 0.2053 & -0.1363 \\
\hline Model 27 & 0.0696 & 0.1129 & 0.0618 & 0.0005 & 0.2598 & 0.4395 & -0.0214 & -0.2233 & & 0.1129 & -0.2271 & 0.0696 & 0.1813 & -0.1414 \\
\hline Model 1.1 (w) & 0.0777 & 0.1646 & & -0.0092 & & 0.2515 & -0.0961 & -0.183 & -0.0092 & 0.1646 & -0.2699 & 0.0777 & 0.2515 & -0.183 \\
\hline Model 2.1 (w) & 0.0693 & 0.1609 & 0.0626 & -0.0156 & 0.2592 & 0.2725 & -0.0806 & -0.1788 & -0.0156 & 0.1609 & -0.2771 & 0.0693 & 0.2459 & -0.1922 \\
\hline Multi 1 & -0.0226 & 0.1748 & 0.065 & -0.0545 & 0.411 & 0.2411 & -0.0362 & -0.0702 & -0.0545 & 0.1748 & -0.1444 & -0.0226 & 0.2451 & -0.0749 \\
\hline
\end{tabular}




\section{Appendix C}

\begin{tabular}{|c|c|c|c|c|c|c|}
\hline \multirow[b]{2}{*}{ Parameter } & & & Jectasting actur & 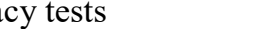 & & \\
\hline & $\begin{array}{l}\text { Root Mean } \\
\text { Square } \\
\text { Error } \\
\text { (RMSE) }\end{array}$ & $\begin{array}{c}\text { Mean } \\
\text { Absolute } \\
\text { Error } \\
\text { (MAE) }\end{array}$ & $\begin{array}{c}\text { Mean } \\
\text { Percentage } \\
\text { Error (MPE), } \\
\%\end{array}$ & $\begin{array}{c}\text { Mean Absolute } \\
\text { Percentage } \\
\text { Error } \\
\text { (MAPE),\% }\end{array}$ & $\begin{array}{c}\text { (Theil's } \\
\text { U) }\end{array}$ & $\mathbf{R}^{2}$ \\
\hline \multicolumn{7}{|c|}{ Standard linear multiple regressions } \\
\hline Model 1 & 0.1309 & 0.1113 & -3.0507 & 107.28 & 0.6955 & 0.495 \\
\hline Model 1.1(w) & 0.1273 & 0.1013 & 4.7343 & 95.0821 & 0.6784 & 0.522 \\
\hline Model 2 & 0.1285 & 0.1046 & -0.5218 & 96.827 & 0.6870 & 0.513 \\
\hline Model 2.1(w) & 0.1260 & 0.0997 & 5.4352 & 90.3987 & 0.6767 & 0.532 \\
\hline \multicolumn{7}{|c|}{ ARMA, ARMAX models } \\
\hline Model 3 & 0.2058 & 0.1741 & 103.8938 & 141.4790 & 0.8682 & -0.247 \\
\hline Model 4 & 0.1877 & 0.1502 & 94.8069 & 109.0351 & 0.9447 & -0.037 \\
\hline Model 5 & 0.1291 & 0.1107 & 1.3556 & 104.9 & 0.6820 & 0.508 \\
\hline Model 6 & 0.1408 & 0.1156 & 7.7027 & 110.75 & 0.6868 & 0.416 \\
\hline Model 7 & 0.1411 & 0.1167 & 16.021 & 107.84 & 0.7054 & 0.413 \\
\hline Model 8 & 0.1321 & 0.1164 & -0.1606 & 113.63 & 0.6942 & 0.485 \\
\hline Model 9 & 0.1429 & 0.1195 & 4.5689 & 117.73 & 0.6941 & 0.398 \\
\hline Model 10 & 0.1439 & 0.1246 & 8.2045 & 123.69 & 0.6978 & 0.390 \\
\hline \multicolumn{7}{|c|}{ Quantile regressions } \\
\hline Model 11 & 0.1301 & 0.1025 & 0.9795 & 90.522 & 0.7004 & 0.501 \\
\hline Model 12 & 0.1313 & 0.1033 & -0.8925 & 93.267 & 0.7036 & 0.476 \\
\hline Model 13 & 0.1240 & 0.1035 & 10.751 & 92.638 & 0.6675 & 0.546 \\
\hline Model 14 & 0.1279 & 0.1030 & 2.9263 & 97.844 & 0.6814 & 0.518 \\
\hline Model 15 & 0.1254 & 0.1075 & 13.893 & 98.023 & 0.6639 & 0.536 \\
\hline Model 16 & 0.1316 & 0.1134 & 19.273 & 111.13 & 0.7006 & 0.490 \\
\hline \multicolumn{7}{|c|}{ Logit and Probit regressions } \\
\hline Model 17 & 0.3463 & 0.2310 & - & - & - & - \\
\hline Model 18 & 0.3475 & 0.2286 & - & - & - & - \\
\hline Model 19 & 0.3427 & 0.2261 & - & - & - & - \\
\hline Model 20 & 0.3443 & 0.2238 & - & - & - & - \\
\hline \multicolumn{7}{|c|}{ Piecewise linear regressions } \\
\hline Model 21 & 0.0999 & 0.0796 & -22.7047 & 63.3832 & 0.5485 & 0.706 \\
\hline Model 22 & 0.1162 & 0.0889 & 6.9187 & 78.8485 & 0.6600 & 0.602 \\
\hline \multicolumn{7}{|c|}{ Non-linear regressions (for the factors) } \\
\hline Model 23 & 0.1222 & 0.0949 & 16.248 & 92.625 & 0.6805 & 0.560 \\
\hline Model 24 & 0.1347 & 0.1048 & 19.289 & 91.271 & 0.6788 & 0.466 \\
\hline \multicolumn{7}{|c|}{ Non-linear regressions (for the estimated parameters) } \\
\hline Model 25 & 0.1236 & 0.0958 & 12.1089 & 85.7383 & 0.6838 & 0.550 \\
\hline Model 26 & 0.1352 & 0.1028 & 19.706 & 88.422 & 0.6858 & 0.461 \\
\hline Model 27 & 0.1366 & 0.1081 & 14.342 & 95.903 & 0.7165 & 0.450 \\
\hline \multicolumn{7}{|c|}{ Consensus forecast } \\
\hline Multi 1 & 0.0973 & 0.0601 & 16.2657 & 43.0299 & 0.6472 & 0.721 \\
\hline
\end{tabular}




\section{Appendix D}

Figure D.1: Forecasting accuracy tests

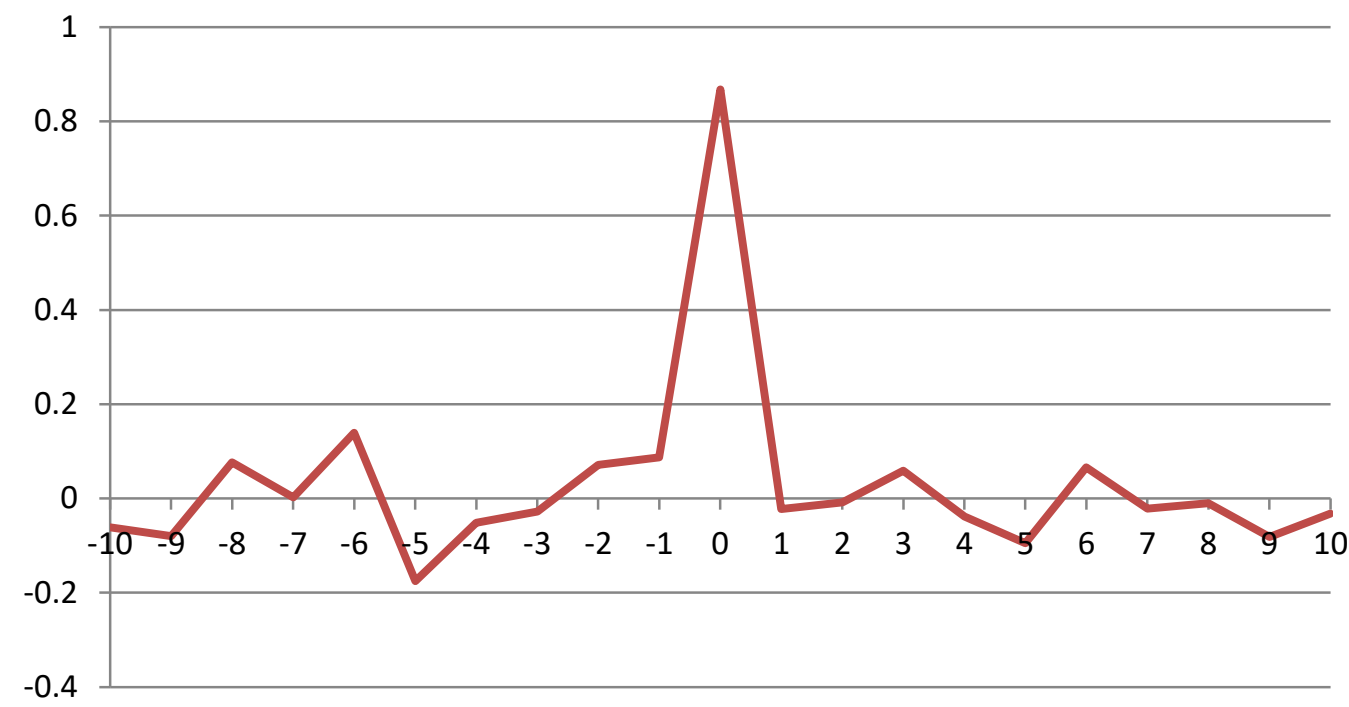

Figure D.1: Cross-correlation between Bitcoin log returns and the frequency of the Delta parameter over the whole sample period for different leads and lags

This figure displays the correlation coefficients between Bitcoin log returns and Delta over the whole sample period with lags in the interval $[-10 \ldots+10]$. 


\section{Appendix E}

Table E.1: Regression analysis results: Bitcoin log returns

\begin{tabular}{|c|c|c|c|c|}
\hline \multirow[t]{2}{*}{ Parameter } & Model 1 & Model 1.1 & Model 2 & Model 2.1 \\
\hline & Delta & Delta & $\begin{array}{c}\text { Frequency of } \\
\text { negative and } \\
\text { positive } \\
\text { abnormal } \\
\text { returns as } \\
\text { separate } \\
\text { variables }\end{array}$ & $\begin{array}{c}\text { Frequency of } \\
\text { negative and } \\
\text { positive } \\
\text { abnormal } \\
\text { returns as } \\
\text { separate } \\
\text { variables }\end{array}$ \\
\hline$a_{0}$ & $\begin{array}{l}0.0901 \\
(0.000)\end{array}$ & $\begin{array}{l}0.0777 \\
(0.000)\end{array}$ & $0.0650(0.024)$ & $\begin{array}{l}0.0626 \\
(0.023)\end{array}$ \\
\hline $\begin{array}{l}\text { Coefficient on abnormal returns } \\
\text { (case of Delta) }\end{array}$ & $\begin{array}{l}0.0953 \\
(0.000)\end{array}$ & $\begin{array}{l}0.0868 \\
(0.000)\end{array}$ & - & - \\
\hline $\begin{array}{l}\text { Coefficient on the frequency of } \\
\text { negative abnormal returns }\end{array}$ & - & & $-0.0904(0.000)$ & $\begin{array}{l}-0.0849 \\
(0.000)\end{array}$ \\
\hline $\begin{array}{l}\text { Coefficient on the frequency of } \\
\text { positive abnormal returns }\end{array}$ & - & & $0.0993(0.000)$ & $\begin{array}{l}0.0916 \\
(0.000)\end{array}$ \\
\hline$R^{2}$ & 0.7721 & 0.7652 & 0.7767 & 0.7722 \\
\hline$p$-value & 0.0000 & 0.0000 & 0.0000 & 0.0000 \\
\hline Log Likelihood & 34.3527 & 33.3493 & 35.0369 & 34.3603 \\
\hline Model Standard Error & 0.1471 & 0.1493 & 0.1467 & 0.1482 \\
\hline AIC & -64.7054 & -62.6986 & -64.0739 & -62.7206 \\
\hline $\mathrm{BIC}$ & -60.2960 & -58.2892 & -57.4598 & -56.1066 \\
\hline * P-values are in parentheses & & & & \\
\hline
\end{tabular}

34 


\section{Appendix F}

Table F.1: Parameter estimates for the best ARMA models

$\begin{array}{lcc}\text { Parameter } & \begin{array}{c}\text { Model 3: } \\ \text { ARMA(2,2) }\end{array} & \begin{array}{c}\text { Model 4: } \\ \text { ARMA(3,3) }\end{array} \\ a_{0} & 0.0516(0.2103) & 0.0513(0.1887) \\ \psi_{t-1} & 0.3486(0.006) & - \\ \psi_{t-2} & -0.7381(0.000) & -0.3874(0.000) \\ \psi_{t-3} & - & -0.6209(0.000) \\ \theta_{t-1} & -0.3418(0.000) & - \\ \theta_{t-2} & 1.000(0.000) & 0.5790(0.000) \\ \theta_{t-3} & - & 0.6487(0.000) \\ \boldsymbol{R}^{2} & & 0.0373 \\ \text { Log Likelihood } & 0.0562 & -13.3259 \\ \text { Model Standard Error } & -12.3733 & 0.2885 \\ \text { AIC } & 0.2831 & 38.6518 \\ \text { BIC } & 36.7466 & 51.8800\end{array}$

This table presents the coefficient estimates and p-values (in parentheses) from the ARMA models. The first column reports the parameter estimates for Bitcoin log returns $(Y)$, the second column shows the parameter estimates for Model 3: ARMA $(2,2)$; the third column for Model 4: $\operatorname{ARMA}(3,3)$. 


\section{Appendix G}

Table G.1: Estimated parameters for the ARMAX models: regressors $F^{+}$and $F^{-}$

\begin{tabular}{|c|c|c|c|}
\hline Parameter & $\begin{array}{l}\text { Model } 5 \\
\text { ARMAX(1,1,2) }\end{array}$ & $\begin{array}{l}\text { Model } 6 \\
\text { ARMAX(2,2,2) }\end{array}$ & $\begin{array}{l}\text { Model } 7 \\
\text { ARMAX }(3,3,2)\end{array}$ \\
\hline$a_{0}$ & $0.0710(0.0674)$ & $0.0678(0.0193)$ & $0.0653(0.0185)$ \\
\hline$\psi_{t-1}$ & $0.9488(0.000)$ & $-1.3021(0.000)$ & - \\
\hline$\psi_{t-2}$ & - & $-0.7734(0.000)$ & $-0.1899(0.0932)$ \\
\hline$\psi_{t-3}$ & - & - & $-0.8078(0.000)$ \\
\hline$\theta_{t-1}$ & $-0.8963(0.000)$ & $0.06834(0.000)$ & - \\
\hline$\theta_{t-2}$ & - & $1.0000(0.000)$ & $0.3585(0.000)$ \\
\hline$\theta_{t-3}$ & - & - & $0.8009(0.000)$ \\
\hline$a_{1}$ & $0.0996(0.000)$ & $0.1020(0.000)$ & $0.0973(0.000)$ \\
\hline$a_{2}$ & $-0.0927(0.000)$ & $-0.0936(0.000)$ & $-0.0886(0.000)$ \\
\hline$R^{2}$ & 0.7817 & 0.7912 & 0.7916 \\
\hline Log Likelihood & 35.8117 & 37.6596 & 37.5804 \\
\hline Model Standard Error & 0.1416 & 0.1342 & 0.1348 \\
\hline AIC & -59.6234 & -59.3193 & -59.1608 \\
\hline BIC & -46.3952 & -41.6817 & -41.5232 \\
\hline
\end{tabular}

This table presents coefficient estimates and p-values (in parentheses) from the ARMAX models. The first column reports parameter estimates for Bitcoin log returns (Y), the second column shows parameter estimates for model 5, the third column for model 6 and the fourth column for model 7 . 
Table G.2: Estimated parameters for the ARMAX models: regressor Delta

$\begin{array}{lccc}\text { Parameter } & \begin{array}{l}\text { Model 8 } \\ \text { ARMAX(1,1,1) }\end{array} & \begin{array}{c}\text { Model 9 } \\ \text { ARMAX(2,2,1) }\end{array} & \begin{array}{c}\text { Model 10 } \\ \text { ARMAX(3,3,1) }\end{array} \\ a_{0} & 0.0914(0.005) & 0.0913(0.000) & 0.0926(0.007) \\ \psi_{t-1} & 0.9445(0.000) & -1.2701(0.000) & -0.3639(0.020) \\ \psi_{t-2} & - & -0.7467(0.000) & 0.4780(0.000) \\ \psi_{t-3} & - & - & 0.7355(0.000) \\ \theta_{t-1} & -0.8828(0.000) & 1.402(0.000) & 0.5240(0.000) \\ \theta_{t-2} & - & 1.0000(0.000) & -0.2618(0.050) \\ \theta_{t-3} & - & - & -0.8914(0.000) \\ a_{1} & - & 0.0982(0.000) & 0.0992(0.000) \\ \boldsymbol{R}^{2} & -0.0966(0.000) & 0.7882 & 0.7942 \\ \text { Log Likelihood } & 0.7793 & 37.1313 & 38.1502 \\ \text { Model Standard Error } & 35.4427 & 0.1352 & 0.1330 \\ \text { AIC } & 0.1424 & -60.2627 & -58.3005 \\ \text { BIC } & -60.8857 & -44.8298 & -38.4582\end{array}$

This table presents coefficient estimates and p-values (in parentheses) from the ARMAX models. The first column reports parameter estimates for Bitcoin log returns (Y), the second column shows parameter estimates for model 8, the third column for model 9 and the fourth column for model 10 . 


\section{Appendix H}

Table H.1: Estimated parameters for the quantile regression: case of $Q=0.4$

$\begin{array}{lcc}\text { Parameter } & \begin{array}{c}\text { Model 11 } \\ F_{t}^{+}, F_{t}^{-}\end{array} & \begin{array}{c}\text { Model 12 } \\ \text { Delta }\end{array} \\ a_{0} & 0.0257(0.4261) & 0.0489(0.0123) \\ a_{1} & 0.0966(0.000) & 0.0845(0.000) \\ a_{2} & -0.0821(0.000) & - \\ \boldsymbol{R}^{2} & 0.7676 & 0.7477 \\ \text { Log Likelihood } & 34.8065 & 33.7560 \\ \text { Model Standard Error } & 0.1093 & 0.1140 \\ \text { AIC } & -63.6130 & -63.5120 \\ \text { BIC } & -56.9989 & -59.1026\end{array}$

Table H.2: Estimated parameters for the quantile regression: case of $\mathrm{Q}=0.5$

$\begin{array}{lcc}\text { Parameter } & \begin{array}{c}\text { Model 13 } \\ F_{t}^{+}, F_{t}^{-}\end{array} & \begin{array}{c}\text { Model 14 } \\ \text { Delta }\end{array} \\ a_{0} & 0.0414(0.1360) & 0.0810(0.000) \\ a_{1} & 0.1010(0.000) & 0.0889(0.000) \\ a_{2} & -0.0803(0.000) & - \\ \boldsymbol{R}^{2} & 0.7663 & 0.7682 \\ \text { Log Likelihood } & 37.2054 & 33.5500 \\ \text { Model Standard Error } & 0.1055 & 0.1115 \\ \text { AIC } & -68.4109 & -62.9594 \\ \text { BIC } & -61.7968 & -58.5500\end{array}$

Table H.3: Estimated parameters for the quantile regression: case of $\mathrm{Q}=0.6$

$\begin{array}{lcc}\text { Parameter } & \begin{array}{c}\text { Model 15 } \\ F_{t}^{+}, F_{t}^{-}\end{array} & \begin{array}{c}\text { Model 16 } \\ \text { Delta }\end{array} \\ a_{0} & 0.0578(0.0339) & 0.1330(0.000) \\ a_{1} & 0.1060(0.000) & 0.0887(0.000) \\ a_{2} & -0.0825(0.000) & - \\ \boldsymbol{R}^{2} & 0.7522 & 0.7458 \\ \text { Log Likelihood } & 37.2322 & 32.8061 \\ \text { Model Standard Error } & 0.1080 & 0.1173 \\ \text { AIC } & -68.4645 & -61.6123 \\ \text { BIC } & -61.8504 & -57.2029\end{array}$

These tables present coefficient estimates and p-values (in parentheses) from the quantile regression models. The first column reports parameter estimates for Bitcoin log returns (Y), the second and the third column shows parameter estimates for model of interest. 
LEDGER VOL 6 (2021) 17-41

\section{Appendix I}

Table I.1: Logit and Probit regression analysis results

\begin{tabular}{lcccc}
\multicolumn{1}{c}{ Parameter } & \multicolumn{2}{c}{ Logit } & \multicolumn{2}{c}{ Probit } \\
& Model 17 & Model 18 Delta & Model 19 & Model 20 Delta \\
& $F_{t}^{+}, F_{t}^{-}$ & & $F_{t}^{+}, F_{t}^{-}$ & \\
$a_{0}$ & $0.7506(0.140)$ & $0.9782(0.018)$ & $0.4375(0.136)$ & $0.5682(0.014)$ \\
$a_{1}$ & $1.4789(0.000)$ & $1.3846(0.000)$ & $0.8613(0.000)$ & $0.8137(0.000)$ \\
$a_{2}$ & $-1.3585(0.000)$ & - & $-0.7981(0.000)$ & - \\
McFadden R-squared & 0.4759 & 0.4695 & 0.4799 & 0.4742 \\
Log Likelihood & -24.2414 & -24.5353 & -24.0562 & -24.3160 \\
AIC & 54.4829 & 53.0706 & 54.1124 & 52.6320 \\
BIC & 61.0970 & 57.4799 & 60.7265 & 57.0414 \\
The percentage of & 82.1 & 80.6 & 82.1 & 80.6 \\
correctly predicted & & & & \\
cases & & & & \\
LR statistic & $44.0253(0.000)$ & $43.4376(0.000)$ & $44.3958(0.000)$ & $43.8762(0.000)$
\end{tabular}

This table presents coefficient estimates and p-values (in parentheses) from the Logit and Probit regression models. The first column reports parameter estimates for Bitcoin log returns $(Y)$, the second and the third column shows parameter estimates for Logit models, the fourth and the fifth reports Probit models estimates.

Table I.2: Estimated parameters for the piecewise linear regression

$\begin{array}{lcc}\text { Parameter } & \begin{array}{c}\text { Model 21 } \\ F_{t}^{+}, F_{t}^{-}\end{array} & \begin{array}{c}\text { Model 22 } \\ \text { Delta }\end{array} \\ a_{0} & -0.0339(0.359) & 0.0404(0.091) \\ a_{1} & 0.0038(0.820) & 0.0665(0.000) \\ a_{2} & -0.0358(0.002) & 0.0504(0.003) \\ b_{0} & 0.0911(0.002) & - \\ b_{1} & 0.1003(0.000) & - \\ b_{2} & -0.0845(0.000) & - \\ \boldsymbol{R}^{2} & 0.8707 & \\ \text { Log Likelihood } & 53.3363 & 0.8012 \\ \text { Model Standard } & 0.1144 & 38.9128 \\ \text { Error } & & 0.1385 \\ \text { AIC } & -94.6726 & -71.8255 \\ \text { BIC } & -81.4444 & -65.2115\end{array}$

This table presents coefficient estimates and p-values (in parentheses) from the piecewise linear regression models. The first column reports parameter estimates for Bitcoin log returns (Y), the second and the third column shows parameter estimates for the piecewise linear regression models. 


\section{Appendix J}

Table J.1: Non-linear regression model type 1: estimated parameters

$\begin{array}{lcc}\text { Parameter } & \text { Model 23 } & \text { Model 24 } \\ a_{0} & 0.0853(0.000) & 0.0588(0.001) \\ a_{1} & 0.0755(0.000) & 0.0734(0.000) \\ a_{2} & 0.0029(0.004) & 0.0065(0.000) \\ a_{3} & 0.0022(0.013) & 0.0030(0.000) \\ a_{4} & - & -0.0038(0.000) \\ a_{5} & - & 0.0012(0.004) \\ \boldsymbol{R}^{2} & 0.8166 & 0.8783 \\ \text { Log Likelihood } & 41.6371 & 55.3723 \\ \text { Model Standard } & 0.1340 & 0.1109 \\ \text { Error } & & \\ \text { AIC } & & -98.7446 \\ \text { BIC } & -75.2742 & -85.5164\end{array}$

This table presents coefficient estimates and p-values (in parentheses) from the Non-linear regression model type 1. The first column reports parameter estimates for Bitcoin log returns $(\mathrm{Y})$, the second and the third column shows parameter estimates for the Non-linear regression model type 1 . 
Table J.2: Non-linear regression model type 2: estimated parameters

$\begin{array}{lccc}\text { Parameter } & \text { Model 25 } & \text { Model 26 } & \text { Model 27 } \\ a_{0} & 0.0739(0.047) & 0.0658(0.036) & 0.0618(0.026) \\ a_{1} & - & - & - \\ a_{2} & - & 0.0049(0.007) & - \\ a_{3} & - & 0.0032(0.000) & 0.0031(0.000) \\ a_{4} & - & -0.0038(0.000) & -0.0036(0.000) \\ a_{5} & - & - & - \\ a_{6} & - & - & -0.0006(0.005) \\ b & 0.0511(0.008) & 0.0590(0.003) & 0.0481(0.000) \\ c & -0.0589(0.030) & -0.0709(0.011) & -0.0472(0.002) \\ p & 1.2753(0.000) & 1.1776(0.000) & 1.4688(0.000) \\ q & 1.1609(0.000) & 0.9531(0.000) & 1.4018(0.000) \\ \boldsymbol{R}^{2} & 0.7919 & 0.8787 & 0.8814 \\ \text { Log Likelihood } & 37.4026 & 55.4726 & 56.2452 \\ \text { Model Standard } & 0.1439 & 0.1126 & 0.1113 \\ \text { Error } & & & \\ \text { AIC } & -64.8053 & -94.9453 & -96.4904 \\ \text { BIC } & -53.7818 & -77.3078 & -78.8529\end{array}$

This table presents coefficient estimates and p-values (in parentheses) from the Non-linear regression model type 2. The first column reports parameter estimates for Bitcoin log returns (Y), the second, the third and the fourth column shows parameter estimates for the Non-linear regression model type 2.

\section{(cc) BY}

ULLS
Articles in this journal are licensed under a Creative Commons Attribution 4.0 License.

Ledger is published by the University Library System of the University of Pittsburgh as part of its D-Scribe Digital Publishing Program and is cosponsored by the University of Pittsburgh Press. 